\title{
Development and evaluation of a quality assessment instrument for occupational physicians
}

\author{
Willeke E van der Weide, Jos H A M Verbeek, Frank J H van Dijk, Carel T J Hulshof
}

\begin{abstract}
Objectives-To develop and apply a method for assessing the quality of the process of occupational health care for individual patients.

Methods-The scientific literature was studied to develop a method to assess the quality of the process of occupational rehabilitation for workers with low back pain. The method was applied to health care and university workers with low back pain who were rehabilitated by their occupational physicians.

Results-Assessment of quality of care is regarded as a four step approach. Firstly, guidelines should be developed and implemented. Secondly, indicators for quality and criteria to demarcate good and deviant quality were derived from the guidelines. Thirdly, a method for data collection was chosen. Finally, quality was scored. For occupational rehabilitation, there was some deviance from the guidelines for most cases, especially in continuity of care with a deviant rate of $47 \%$. Other indicators deviated from $1.4 \%-17.4 \%$. Occupational physicians agreed on the relevance of the indicators and criteria, but for three indicators they evaluated the criteria as too rigid. They did not agree with their own performance scores in $66 \%$ of the deviant cases.

Conclusion-Assessing the quality of the process of occupational health care with this method is an asset to present methods, but more specific criteria are needed for a more sensitive assessment.
\end{abstract}

The Coronel Institute for Occupational and Environmental Health, University of Amsterdam, Academic Medical Centre, Amsterdam W E van der Weide J H A M Verbeek F J H van Dijk C T J Hulshof

Correspondence to: Dr Willeke E van der Weide, Coronel Institute for Occupational and Environmental Health, University of Amsterdam, Academic Medical Centre, PO Box 22700, $1100 \mathrm{DE}$ Amsterdam, The Netherlands. Tel: 003120 566 4878; Fax 003120697 7161; email:

gsnel@worldaccess.nl

Accepted 27 November 1997

Quality of care attracts increasing interest in different fields of health care-such as hospitals, ambulatory settings, and general practice. ${ }^{1-3}$ Compared with these fields quality assessment in occupational health care is largely undeveloped. Occupational health consultation and occupational rehabilitation are good examples. Occupational rehabilitation is the most time consuming task of occupational physicians in The Netherlands, ${ }^{45}$ but we hardly know what "good quality practice" is and how it should be assessed. At the same time there is an increasing demand for accountability of occupational health services due to commercialisation and competition. To be able to account for the use of economic resources the development of a valid method for quality assessment is of paramount importance.

Unlike most other fields of medicine, in occupational rehabilitation many parties are necessary to yield good results. Apart from patients and occupational physicians, in most cases employers, department staff and colleagues, general practitioners, medical specialists, and insurance companies are involved. Thus, return to work as an outcome variable for occupational rehabilitation is influenced by many variables. Even if the outcome is negative the occupational physicians may have performed quite well. So, it is sensible to look firstly at the process of care. Furthermore, process data are usually more sensitive and more informative measures of quality than outcome data. ${ }^{67}$ Variables to measure the quality of occupational health care are still not readily available. Some studies, especially from the United Kingdom, Finland, and the United States, refer to this topic. ${ }^{8-13}$ However, a clear basis for the definition of good quality practice is often lacking, ${ }^{8-10}$ or the emphasis is on procedures instead of the content of care. ${ }^{11}{ }^{14}$ Therefore, we decided to develop and evaluate a method for defining and measuring the quality of the occupational physician's contribution to occupational rehabilitation.

In this paper we present the development of a method for quality assessment in occupational health care based on publications from other fields of medicine. This method was developed for quality assessment of occupational rehabilitation of workers with low back pain in a research setting, but the situation is comparable with the assessment of quality in everyday practice. In the results section we describe the published findings as well as the choices made for occupational rehabilitation. These two parts are not separated to facilitate understanding. We also report on evaluative aspects of the method.

\section{Methods}

We performed a literature survey in the medline database from 1981 to 1995 . We selected non-specific reviews-that is, not about a specific disease-on practice guidelines, process assessment, peer review, medical audit, health services research, physician practice patterns, clinical protocols, consensus development conferences, diffusion of innovation, and feedback. References in pertinent publications were checked for relevant studies, and we used citations provided by colleagues.

For our quality assessment method we decided firstly on scientific evidence for the efficacy of interventions and of implementation 
methods, secondly on methodological criteria such as assumed validity and reliability, and thirdly on applicability in practice. However, our process of development was restrained by time and budget, both not unusual in practice.

For a first evaluation of the quality assessment method we used the setting of a clinical trial about the efficacy of occupational rehabilitation for healthcare workers and university workers (1995-7). Nineteen occupational physicians from eight occupational health services in The Netherlands participated in this trial. One hundred and twenty consecutive workers who were on sick leave with low back pain for at least 10 days were randomly assigned to an intervention group (an occupational rehabilitation programme $(n=61))$ or to a control group (support by their superior only $(n=59)$ ). Two patients in the intervention group did not visit the occupational physician although 14 patients from the control group did. So, 73 workers received occupational rehabilitation by an occupational physician. We report on 69 of these 73 workers because of missing data of four patients.

At the end of the trial the occupational physicians received a questionnaire for a limited evaluation of the quality assessment method. One occupational physician did not answer the questionnaire. Technical (validity, reliability), process (acceptability), and strategic (utility) criteria were differentiated in the evaluation. ${ }^{15}$

\section{Results}

DEVELOPMENT

The development of a method for assessing quality was divided into four steps. ${ }^{16-23}$ The first step consisted of development, dissemination, and implementation of guidelines taken together. Grimshaw and Russell distinguish these elements. They defined dissemination as interventions aimed at influencing clinicians attitudes, awareness, knowledge, and understanding of guidelines, and implementation as interventions aimed at improving clinicians, compliance with guideline recommendations. ${ }^{24}$ However, in practice all three phases were so closely connected, that we combined them in this first step. In the second step indicators for quality were derived from these guidelines. For every indicator criteria were formulated which demarcated appropriate and deviant care. These indicators and criteria enabled the next step of data collection in the field. The fourth and final step was to set up a scoring method which led to a final assessment of good or deviant quality.

\section{Step 1: development and implementation of} practice guidelines

Guidelines provide systematically developed statements to assist practitioner decisions about appropriate health care for specific clinical circumstances. ${ }^{25}$ It is widely accepted that scientific evidence should form the basis of these guidelines. ${ }^{182627}$ To fill in existing gaps in scientific knowledge "experts" should be consulted to reach consensus, which is supposed to be better than random variation between doctors. ${ }^{28}$ Different structured methods for consultation can be used-such as the nominal group technique, a highly structured meeting with experts, or the Delphi method in which questionnaires are used for consulting experts. ${ }^{29}$ Both methods try to reach a degree of consensus about statements on a certain topic-for example, indications for a specific intervention.

Factors that influence the applicability of guidelines are involvement of practitioners in its construction, and a preliminary trial. The acceptability is affected by the maintenance of professional autonomy, adjustment to local circumstances, and individual instruction. ${ }^{18} 25$ 30-32 Furthermore, clinical behaviour of physicians is influenced by financial incentives or disincentives and by patient characteristics - such as expectations of treatment and level of knowledge. $^{33}{ }^{34}$ Reminders at the time of consultation and patient specific feedback were confirmed to be effective in sustaining practice changes. ${ }^{25} 3235$

Our draft guidelines for occupational rehabilitation for this trial were mainly based on guidelines for general practitioners in different countries ${ }^{36} 37$ and on a review of the literature about effective interventions for patients with low back pain. ${ }^{38}$

The guidelines can be divided into two parts: diagnostics and interventions. Three diagnostic categories for low back pain were distinguished, based on medical history and a sensitive test for nerve root compression, the straight leg raising test. ${ }^{39}{ }^{40}$ Prognostic factors that have been shown to be related to the duration of low back pain should be assessednamely, impairments, ${ }^{41}{ }^{42}$ psychosocial problems, ${ }^{43-48}$ heavy work, ${ }^{49-51}$ organisational problems, ${ }^{49-53}$ and inadequate treatment. ${ }^{54} \mathrm{Ex}-$ perts in occupational medicine and neurology were consulted for comment.

In the second part of the guidelines effective interventions were described in these areas. Encouragement of physical activity and avoiding bed rest were interventions proved to be effective in shortening time until return to work. ${ }^{38}$ Decisions about work related interventions, communication with the treating physicians, and time until follow up consultation had to be based on consensus due to lack of evidence.

In a pilot study, the guidelines were used by a group of eight occupational physicians for 44 patients. In two meetings the guidelines were discussed and adjusted based on experiences with real patients and also on hypothetical cases. When we introduced the guidelines among the physicians for the trial with healthcare workers and university workers, they followed the same process to enhance the acceptability. The flexibility of the guidelines was guaranteed as much as possible by leaving latitude for individual clinical judgement and patient preferences. The occupational physicians had to complete a specific registration form summarising the guidelines, which was not only used for data collection but also for reviewing the guidelines. The medical records of relevant employees were tagged so that the occupational physicians were reminded of the 
Table 1 Performance indicators and criteria for rehabilitation of workers with low back pain

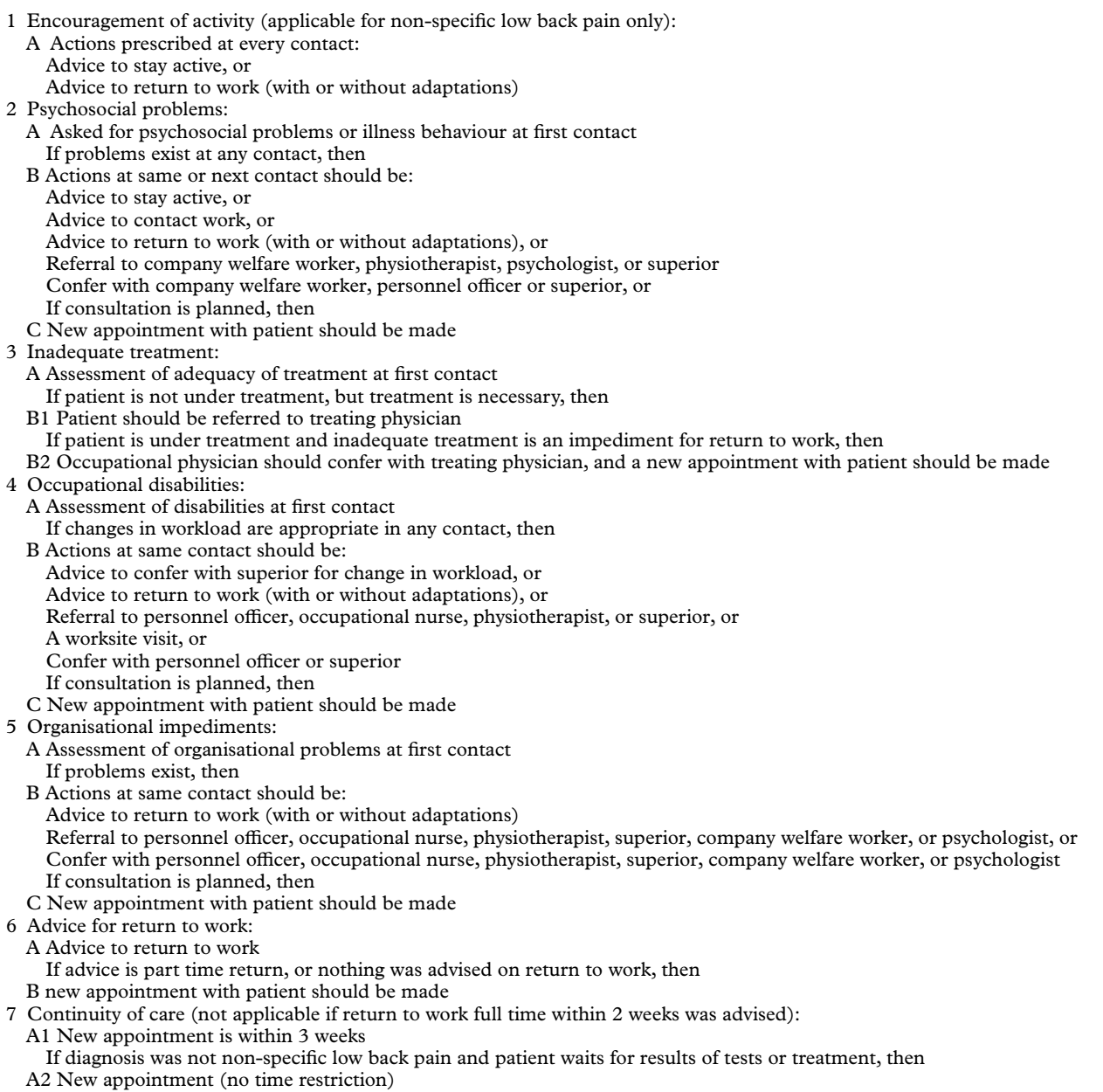

guidelines at the time of consultation. During the research period every second or third month a 90 minute meeting was organised for peer review about actual care of specific patients. Deviations from the guidelines were discussed. Occupational physicians were trained, with help from an actor, in their communication with employees with back pain. One of the researchers visited physicians that enrolled in the study, discussed the guidelines with them, and trained them. The physicians were informed about recent developments in the field.

Step 2: selection of indicators and criteria An indicator for the quality of care was defined as an essential element of care which gives a valid and representative picture of this quality. Indicators can be selected for structure, process, or outcome aspects depending on the element of interest. ${ }^{55}$ Indicators should be made operational by criteria. A criterion answers the question of "what represents appropriate or desirable care?" and demarcates good from deviant care for a specific indicator. However, the content of care for a patient partly depends on specific patient characteristics. Patients that are more severely ill require different or more intense care than others. Therefore, algorithmic criteria should be used which are adaptable to individual patient characteristics. In this "criteria mapping" "branching logic" method, ${ }^{58}$ process criteria are formulated in "if-then" statementsnamely, if a patient has a certain characteristic then the physician should perform a specific action. This method better predicts a favourable outcome of care than applying the same criteria to every patient. ${ }^{156}$ Furthermore, these explicit criteria are objective, can be used by external assessors, and have a high reliability. ${ }^{1659}$

Process indicators can be grouped into categories - for instance, into a diagnostic and therapeutic category, or into categories related to specific problems. Finally, a single visit or a whole care episode can be represented in the indicators. ${ }^{60}$

Because of our interest in the process of care as far as the occupational physician is involved, we focused on the performance of this physician. Therefore, process indicators were called performance indicators. From the guidelines we derived seven performance indicators with explicit criteria in the form of a criteria map (table 1). We used the algorithm that if a problem exists that delays return to work the occupational physician should try to solve that problem. Because of the branching logic, for each indicator several criteria can be met, not 


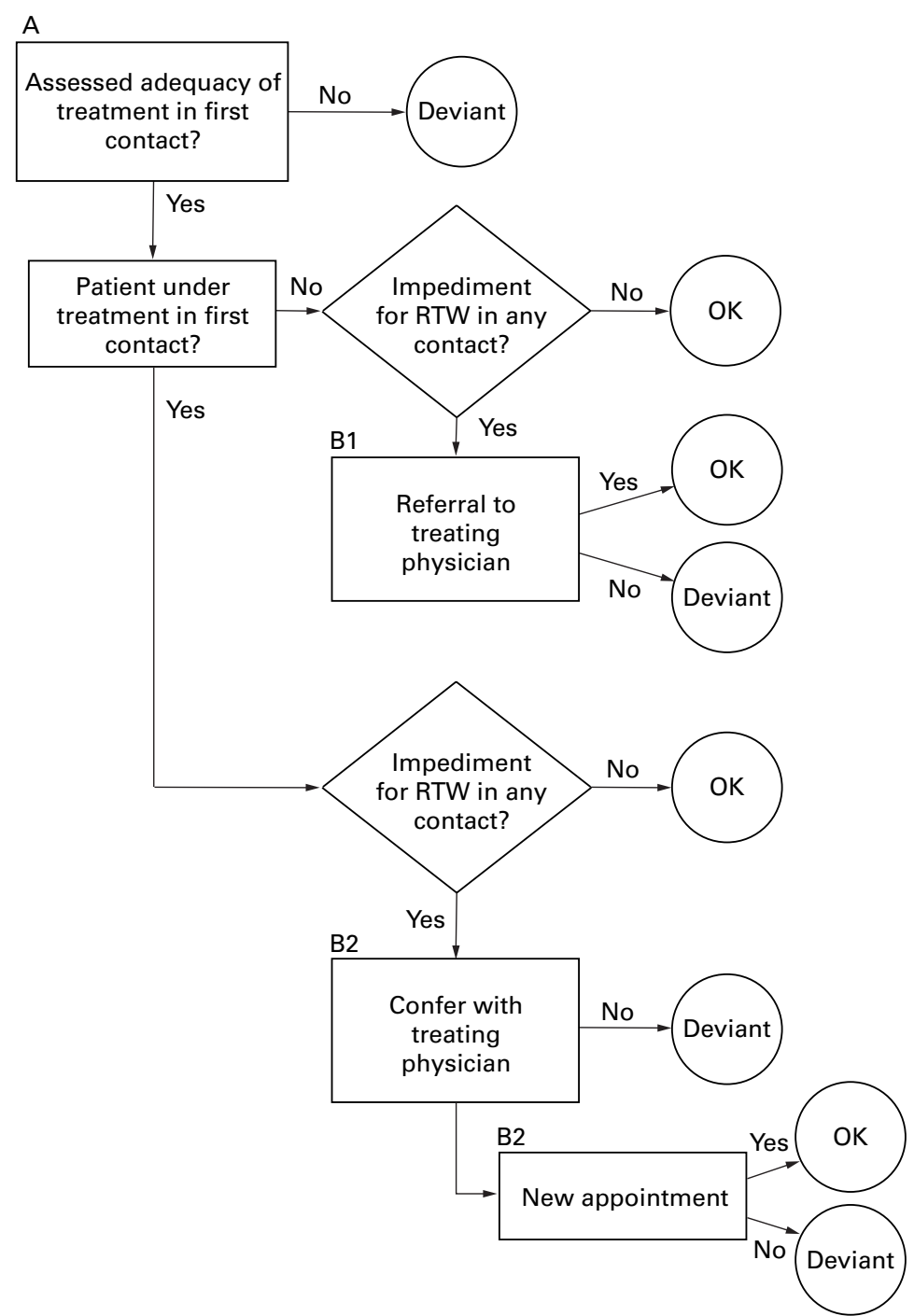

Criteria map for inadequate treatment.

be met (deviant), or be inapplicable. The example (figure) shows the criteria for inadequate treatment. For every indicator criteria were formulated for a whole episode, from the first consultation until return to work. The criteria for each indicator were thoroughly discussed between the two assessors (WvdW,JV) on the basis of real cases after which the definition of diagnostic categories, organisational impediments, and occupational disabilities was refined.

Table 2 Performance scores and rates for occupational rehabilitation of 69 workers with low back pain

\begin{tabular}{llc}
\hline & \multicolumn{2}{l}{ Performance rate of cases $(n(\%))$} \\
\cline { 2 - 3 } Outcome variables & Not deviant & Deviant \\
\hline Encouragement of activity & $48(85.7)$ & $8(14.3)$ \\
Psychosocial problems & $63(91.3)$ & $6(8.7)$ \\
Inadequate treatment & $57(82.6)$ & $12(17.4)$ \\
Occupational disabilities & $68(98.6)$ & $1(1.4)$ \\
Organisational impediments & $66(95.7)$ & $3(4.3)$ \\
Advice for return to work & $67(97.1)$ & $2(2.9)$ \\
Continuity of care & $32(53.3)$ & $28(46.7)$ \\
Technical competence score (1-6) & Performance score of cases $(n(\%))$ \\
Case performance score $(1-7)$ & $44(63.8)$ & $25(36.2)$ \\
& $26(37.7)$ & $43(62.3)$ \\
\hline
\end{tabular}

$\star 13$ Cases not applicable.

$\star \star 9$ Cases not applicable.
Step 3: data collection

Different means of data collection can be used, but it should be noted that the results are often not comparable. Gerbert and Hargreaves concluded from their study that physician and patient interviews, chart audit, video taping and audio taping capture different aspects of care. Agreement between raters was comparable and high for all methods. ${ }^{12} 5861$ The advantages of using medical records are low costs and high acceptability for physicians. ${ }^{61}{ }^{62} \mathrm{How}-$ ever, medical records contain no information about the interpersonal process, and also are often found to be incomplete especially for advisory contents. ${ }^{27} 6163$ The disadvantage of observation is the presence of an observer, which can lead to distortions in compliance with the guidelines.

We gathered the information with forms made for this specific purpose because we were not sure that the medical record would contain sufficient information. The forms were explained during the first meeting and tested by the occupational physicians on their patients between the first and second meeting. For each contact a form had to be completed. The forms from every episode of low back pain were scored on the criteria.

Step 4: assessment of performance

A choice has to be made for a scoring method assessing the performance of the whole process or performance for specific indicators. Performance of occupational health services and of individual physicians might also be of interest. A simple, unweighted summed score of performance has advantages, but assumes that the different indicators throughout the whole process are equally important. ${ }^{64}$ Another consideration is that performance scores for different indicators give more detailed information about specific aspects of care. ${ }^{1658}$

For each case, we scored performance on the specific indicators with a binary outcome (deviant or not) for the whole episode, independent of the number of consultations. Encouragement of activity and continuity of care could also have a third outcome, inapplicable. Performance for an indicator was deviant from the guidelines if one or more of the criteria were not met for that indicator. In case the criteria could not be applied due to forms that were not fully completed, an indicator was also scored as deviant, unless the right answer could be retrieved otherwise.

A performance rate for an indicator was computed as the number of deviant cases for that specific indicator divided by the total number of applicable cases. A case performance score was defined as deviant if one or more indicators for that case were deviant. The performance rates for the specific occupational health services were calculated as well, but we did not find relevant differences. Due to small numbers we did not calculate performance rates for individual physicians.

Table 2 shows performance scores and rates. Apparently, it was quite difficult to comply with the guidelines for all indicators, as $62 \%$ of all cases were deviant in at least one indicator. 
Table 3 Performance indicators for the quality of rehabilitaton of workers with low back pain and opinion of occupational physicians $(n=18)$

\begin{tabular}{|c|c|c|c|c|c|c|}
\hline \multirow[b]{2}{*}{ Performance indicators } & \multicolumn{3}{|c|}{$\begin{array}{l}\text { Relevance according to occupational physicians } \\
(n(\%))\end{array}$} & \multicolumn{3}{|c|}{$\begin{array}{l}\text { Correct criteria according to occupational } \\
\text { physicians }(n(\%))\end{array}$} \\
\hline & Relevant & Neutral & Not relevant & Too mild & Correct & Too rigid \\
\hline Encouragement of activity & $15(83.3)$ & $2(11.1)$ & $1(5.6)$ & $2(11.1)$ & $7(38.9)$ & $9(50.0)$ \\
\hline Psychosocial problems ${ }^{\star}$ & $14(87.5)$ & $2(12.5)$ & - & - & $12(70.6)$ & $5(29.4)$ \\
\hline Inadequate treatment & $12(66.7)$ & $6(33.3)$ & - & - & $9(50.0)$ & $9(50.0)$ \\
\hline Occupational disabilities & $17(94.4)$ & $1(5.6)$ & - & $1(5.6)$ & $15(83.3)$ & $2(11.1)$ \\
\hline Organisational impediments & $16(88.9)$ & $1(5.6)$ & $1(5.6)$ & $2(11.1)$ & $13(72.2)$ & $3(16.7)$ \\
\hline Advice for return to work & $16(88.9)$ & $1(5.6)$ & $1(5.6)$ & $4(22.2)$ & $13(72.2)$ & $1(5.6)$ \\
\hline Continuity of care & $11(61.1)$ & $6(33.3)$ & $1(5.6)$ & $1(5.6)$ & $9(50.0)$ & $8(44.4)$ \\
\hline
\end{tabular}

^Accounted for two missing values for relevance and one missing value for correct criteria.

This is mainly due to continuity of care. Therefore, we also assessed the technical competence separately by summing the other six indicators. Thirty six per cent of the cases were scored as deviant on technical competence. Especially encouragement of activity and inadequate treatment contributed to a deviant score for a specific case.

\section{EVALUATION}

The validity of indicators and criteria was assessed by asking the opinion of the participating occupational physicians on their relevance and appropriateness. All indicators were valued as relevant by most of the physicians (table 3). Least valued were the relevance of inadequate treatment, involving communication with treating physicians, and continuity of care, a follow up every third week with a few defined exceptions. The formulation of the criteria of these two indicators and the criteria for encouragement of activity, was assessed as too rigid by almost half of the occupational physicians. This was based on practical reasons and reasons of assumed effectiveness. For instance, a follow up every three weeks (continuity of care) was valued as desirable, but not always possible due to holidays, lack of time, a longer duration of a treatment plan of a physiotherapist, or few oportunities at the work site. For communication with treating physicians (inadequate treatment), the occupational physicians wanted a more facultative definition, dependent on assumed effectiveness. The encouragement of activity should, according to the disagreeing physicians, be dependent on the patient's own initiative. According to most of the physicians, the criteria were correctly formulated for the other four indicators.

For the quality of data collection, the registration forms were accepted by and understandable for the occupational physicians. However, it turned out from the questionnaires that the registration forms of eight cases were not fully completed, meaning that the validity was not optimal. We assessed agreement between raters by comparing the assessment of the seven indicators of 20 cases by two raters. The $\kappa$ statistic $(0.88)$ was satisfactory.

Case performance scores were returned to the occupational physicians as feedback for their own performance. The $\kappa$ statistic for agreement between our and their rating was not high (0.46). They disagreed in $66 \%$ of cases with their own deviant performance score.

\section{Discussion}

We present a method for the evaluation of the activities of occupational physicians. The method is objective with explicit criteria for quality assessment and the agreement between raters was good. This explicit method is an alternative for a medical audit as described by Agius et al..$^{8-10}$ They presented no guidelines, explicit indicators, or criteria. So, it is difficult to discuss the method they used and to compare the results of their studies with others. A simple method we used ourselves in an audit of occupational health care for employees with low back pain is also not comparable, because of uniform criteria for each patient. ${ }^{65}$ Only the occupational health care study of Law et al resembles our method. ${ }^{12}$ They used criteria mapping to assess occupational therapists' competencies for self care problems of their patients. The basis for their map was formed by assessment of activities of daily living, among which one item referred to the vocational situation. However, they did not specify what kind of interventions could be considered in an intervention plan.

We evaluated different aspects of our quality assessment method, but we did not assess the validity of the guidelines. This validity is best guaranteed if the different elements are evidence-based. However, the evidence about effective interventions was small: only encouragement of activity for patients with nonspecific low back pain had been proved to be effective. ${ }^{36-38} 6667$ The other interventions were reached by consensus. These interventions could not always be defined as specific as would be desirable to guarantee professional autonomy. On the other hand, this autonomy should enhance the acceptability. Also a consensus process improves the implementation and thereby the acceptability. ${ }^{22}$ We did evaluate the acceptability implicitly by getting everyone's agreement after the first two meetings. We tried to improve the change in practice by combining different strategies to maximise compliance. We used almost all methods advocated in the scientific literature. ${ }^{18}$ Therefore, in theory the implementation step was optimal.

We assessed the content validity by inquiring about relevance and formulation as perceived by the occupational physicians. Interestingly, 
they objected to the criteria for three performance indicators that they agreed on at the construction of the guidelines. These objections were directed at the indicators with the lowest scores. So, in practice, the physicians acted less strictly than formulated in the guidelines. Sometimes, they considered it to be difficult or even inappropriate to act in accordance with the ideal guidelines. However, we dispute their comments. The criteria for encouragement of activity were formulated to encourage adjusted work at home or at work, so it was less strictly defined as interpreted by the physicians. Furthermore, this is the only evidence-based intervention, so we think that it remains important to stimulate patients, even when they are already active. Good performance on continuity of care can be hampered by internal problems - such as lack of time-or external ones-such as high workload or prolonged treatment plans of the physiotherapist-but these are exactly the factors that can prolong the duration of sick leave. It is important to prevent these internal, organisational problems and to intervene in the case of external problems. The assessment of inadequate treatment as too rigid was based on assumed effectiveness. We think that it is practically impossible to define criteria for exceptional cases, for which communication with treating physicians is useless. Furthermore, it can never be assessed whether communication with treating physicians is really ineffective unless this communication is obligatory when treatments hinder the return of patients to work.

These difficulties with action related to curative treatment correspond to a recent publication about problems in the cooperation between the two parties. ${ }^{68}$ In that study it was shown that the main bottleneck for cooperation was the unclear position of the occupational physician. However, the necessity for improvements was recognised by both parties and therefore it is important to show the effectiveness of this cooperation.

Briefly, in practice it will be both difficult and important to strive for optimal care as defined by the criteria. Although occupational physicians considered that the criteria were too rigid, we tend to think that the list of interventions that were defined as appropriate was too long and performance deviated only slowly. More specific guidelines and criteria are needed for a more sensitive quality assessment, but this is very complicated. A lot of unknown factors influence the process, and the specific criteria should incorporate those factors. A step forward in the process of developing more specific guidelines would be an appropriate assessment of psychosocial and disability problems. In a new version of the guidelines, we included questionnaires for both assessments. ${ }^{47}$ 69-71 The usefulness and effectiveness of these questionnaires should be evaluated in further research.

The comments of the occupational physicians on their own performance scores were mainly related to the difference between general criteria and specific individual circumstances which can explain deviations. They did not agree with the deviant performance scores in two thirds of the cases. It is difficult to judge whether they were right in their own cases. It might be related to the actor-observer phenomenon: actors tend to ascribe their behaviour more to circumstances than observers do. ${ }^{72}$ To unravel this problem, the performance scores can be related to other indicators of the quality of occupational rehabilitation. Other indicators are, for example, realisation of planned adjustments at the worksite and satisfaction of the employee. This relation with other process and outcome measurements refers to the strategic or useful quality of our method. Until now, too little attention has been paid to this quality aspect. In further analyses this question about relation with other quality indicators will be considered.

The performance indicators assess the technical quality and continuity of care, which cover only a small part of quality. Communication and interpersonal manner were not assessed. This restriction was practically based, as observational techniques were not applicable for our trial, but it is also difficult to define criteria for appropriate communication. It should be investigated whether satisfaction questionnaires for employees can validly assess these aspects.

We did not use medical records because we expected incomplete recording. ${ }^{61}$ Instead, we chose specific registration forms. These forms were at the same time a manual of the guidelines. It seemed that the most objective criterion, the follow up, was the most deviant one. Possibly the performance scores we assessed were too optimistic. On the other hand, the physicians did not know how to fill in the forms for a good performance score, because they were not informed about the evaluation method. It also seemed that in a few cases the registration forms were not adequately completed. It would have been more appropriate to use a method of quality assessment with a broader base, and time could have been saved by the use of computerised registrations and evaluations.

\section{Conclusion}

We used this method to assess compliance of physicians in a randomised clinical trial, but it is also applicable for evaluation purposes in such situations as medical audit. By contrast with our method, some quality systems - such as vocational training and certification of occupational health services or professionals - cannot detect gaps in performance. We think that these gaps should be the base for further discussion on separating real deviant performance from those cases with acceptable reasons for its deviance. Our method can be used both for a single evaluation and for a continuing process of improving occupational health care. We conclude that assessing the quality of the work of occupational physicians is evolving and therefore is not without problems. A challenge for the future remains. If a method of quality assessment were to be applied in practice, it would be more appropriate and time saving to use computerised registrations and evaluations. 
1 Casparie AF. Medical audit in The Netherlands: experience over 22 years. $\mathcal{F}$ Epidemiol Community Health 1995;49:5578 .

2 Palmer RH, Louis TA, Hsu LN, et al. A randomized controlled trial of quality assurance in 16 ambulatory care practices. Medical Care 1985;23:751-70.

3 Grol R, Wensing M, Jacobs A, et al. Quality assurance in general practice. The state of the art in Europe. Utrecht: Nederlands Huisartsen Genootschap, 1993.

4 Docter HJ, Kuitert HDWB. Tijdsbesteding bedrijfsartsen en andere deskundigen in arbodiensten. (Spending of time of occupational physicians and other professionals in occupational health services.) Tijdschrift voor Bedrijfs-en Verzekeringsgeneeskunde 1996;4:203-13.

5 Smits PBA, Kroon PJ, Verbeek JHAM. Tijdsbesteding van bedrijfsartsen. (Spending of time of occupational physicians.) Tijdschrift voor Bedrijfs-en Verzekeringsgeneeskunde 1996;4:9-13.

6 Brook RH, McGlynn EA, Cleary PD. Quality of health care. Part 2: measuring quality of care. $N$ Engl f Med 1996;335: $966-70$.

7 Davies HT, Crombie IK. Assessing the quality of care. BMF

8 Agius RM, Seaton A, Lee RJ. Audit of sickness absence and fitness-for-work referrals. Occup Med 1995;45:125-30.

9 Agius RM, Lee RJ, Symington IS, et al. An audit of occupa151-7.

10 Agius RM. Peer review audit in occupational medicine. four nal of the Society of Occupational Medicine 1990;40:87-88.

11 Antti-Poika $M$. Implementation of a quality system for the examination of occupational diseases. Occup Med 1995;45: 298-304.

12 Law M, Ryan B, Townsend E, et al. Criteria mapping: a method of quality assurance. Am $\mathcal{F}$ Occup Ther $1989 ; 43$ : 104-09.

13 Young JM. The fifth report of the Joint National Committee on Detection, Evaluation, and Treatment of High Blood Pressure: a resource for occupational health. Fournal of the American Association of Occupational Health Nurses 1995;43: 301-5.

14 Hulshof CTJ, Verbeek JHAM, Van Dijk FJH, et al. How well are we doing? Evaluation research in occupational health services. A systematic review of empirical studies. In Hulshof CTJ. Prevention and control of adverse effects of whole-body vibration. An evaluation study in occupational health services. Amsterdam: Coronel Institute, University of Amsterdam, 1998;73-103.

15 Van Dijk FJ, De Kort WL, Verbeek JH. Quality assessment of occupational health services instruments. Occup Med 1993;43(suppl 1):S28-33

16 Ashton CM, Kuykendall DH, Johnson ML, et al. A method of developing and weighting explicit process of care criteria

17 Palmer RH, Nesson HR. A review of methods for ambulatory medical care evaluations. Med Care 1982;20: $758-781$.

18 Klazinga NS. Compliance with practice guidelines: clinical autonomy revisited [review]. Health Policy 1994;28:51-66.

19 Marwick J, Grol R, Borgiel A. Quality assurance for family doctors. Report of the Quality Assurance Working Party World Organisation of Family Doctors. Jolimont, Australia: World Organisation of National Colleges, Academies and Academic Associations of General Practitioners/Family Physicians, 1992

20 Roche N, Durieux P. Clinical practice guidelines: from methodological to practical issues. Intensive Care Medicine 1994;20:593-601.

21 Lawthers AG, Palmer RH, Edwards JE, et al. Developing and evaluating performance measures for ambulatory care and evaluating performance measures for ambulatory care quality: a preliminary report of the DEMPAQ

22 Thomson R, Lavender M, Madhok R. How to ensure that guidelines are effective. BMF 1995;311:237-42.

23 Roland M, Coulter A. Hospital referrals. Oxford: Oxford University Press, 1992.

24 Grimshaw JM, Russell IT. Achieving health gain through clinical guidelines. II. Ensuring guidelines change medical practice. Quality in Health Care 1994;3:45-52.

25 Grimshaw JM, Russell IT. Effect of clinical guidelines on medical practice: a systematic review of rigorous evaluations. Lancet 1993;342:1317-22.

26 Grol R. Development of guidelines for general practice care. Br F Gen Pract 1993;43:146-51.

27 Donabedian A. The quality of care. How can it be assessed? fAMA 1988;260:1743-8.

28 Berwick DM. Health services research and quality of care. Assignments for the 1990s. Med Care 1989;27:763-71.

29 Jones J, Hunter D. Consensus methods for medical and health services research. $B M \mathcal{F}$ 1995;311:376-80.

30 Schellevis FG, van Eijk JT, van den Lisdonk EH, et al. Implementing guidelines in general practice. Evaluation of process and outcome of care in chronic diseases. Int $\mathcal{F} Q$ ual Health Care 1994;6:257-66.

31 Fardy HJ, Jeffs D. Focus groups: a method for developing consensus guidelines in general practice. Fam Pract 1994;11:325-9.

32 Wensing $M$, Grol R. Single and combined strategies for implementing changes in primary care: a literature review [review]. Int $\mathcal{F}$ Qual Health Care 1994;6:115-32.

33 Robinson MB. Evaluation of medical audit. $\mathcal{f}$ Epidemiol Community Health 1994;48:435-40.

34 Lomas J, Haynes RB. A taxonomy and critical review of tested strategies for the application of clinical practice recommendations: from "official" to "individual" clinical policy. Am f Prev Med 1988;4:77-94.

35 Davis DA, Thomson MA, Oxman AD, et al. Changing physician performance. A systematic review of the effect of continuing medical education strategies. $\mathcal{F} A M A$ 1995;274: $700-5$.

36 Bigos S, Bowyer O, Braen G, et al. Acute low back problems in adults. Clinical practice guideline, quick reference guide number 14. Rockville, MD: US Department of Health and Human Services, Public Health Service, 1994.

37 Rosen M, Breen A, Hamann W, et al. Report of a Clinical Standards Advisory Group Committee on Back Pain. London: HMSO, 1994.

38 Van der Weide WE, Verbeek JHAM, van Tulder MW. Vocational outcome of interventions for low-back pain. Scand $\mathcal{F}$ Work Environ Health 1997;23:165-78.

39 Frank A. Low back pain. BMf 1993;306:901-9.

40 Mazanec DJ. Low back pain syndromes. In: Panzer RJ, Black ER, Griner PR, eds. Diagnostic strategies for common medical problems. Philadelphia: American College of Physicians, 1991.

41 Von Korff M, Deyo RA, Cherkin D, et al. Back pain in primary care. Outcomes at one year. Spine 1993;18:855-62.

42 Roland M, Morris R. A study of the natural history of low back pain. Part II. Spine 1983;8:145-50.

43 Coste J, Delecoeuillerie G, Cohen de Lara A, et al. Clinical course and prognostic factors in acute low back pain: an inception cohort study in primary care practice. BM7 1994;308:577-80

44 Deyo RA, Diehl AK. Psychosocial predictors of disability in patients with low back pain. F Rheumatol 1988;15:1557-64.

45 McNeill TW, Sinkora G, Leavitt F. Psychologic classification of low-back pain patients: a prognostic tool. Spine 1986;11:955-9.

46 Waddell G, Newton $M$, Henderson I, et al. A fear-avoidance beliefs questionnaire (FABQ) and the role of fearavoidance beliefs in chronic low back pain and disability. Pain 1993;52:157-68.

47 Von Korff M, Ormel J, Keefe FJ, et al. Grading the severity of chronic pain. Pain 1992;50:133-49.

48 Waddell G. Understanding the patient with back pain. In: Jayson MIV, ed. The lumbar spine and back pain. Edinburgh: Churchill Livingstone, 1987:419-34.

49 Goertz MN. Prognostic indicators for acute low-back pain. Spine 1990;15:1307-10.

50 Marras WS, Lavender SA, Leurgans SE, et al. Biomechanical risk factors for occupationally related low back disorders. Ergonomics 1995;38:377-410.

51 Buckle P, Stubbs D. The contribution of ergonomics to the rehabilitation of back pain patients. Fournal of the Society of Occupational Medicine 1989;39:56-60.

52 Gates LB. The role of the supervisor in successful adjustment to work with a disabling condition: issues for adjustment to work with a disabling condition: issues for disability policy and practice.

53 Linton SJ. The manager's role in employees successful return to work following back injury. Work Stress 1991;5: $189-95$

54 Bigos SJ, Battie MC. Acute care to prevent back disability. Ten years of progress. Clin Orthop 1987;121-30.

55 Van der Weide WE, Verbeek JHAM, Van Dijk FJH. In Balans, op weg naar richtlijnen voor sociaal-medische begeleiding bij rugklachten. (In Balance, towards guidelines for occupational rehabilitation of low-back pain.) Tijdschrift voor Bedrijfs - en Verzekeringsgeneeskunde 1995;3:220-5.

56 Greenfield S, Cretin S, Worthman LG, et al. Comparison of a criteria map to a criteria list in quality-of-care assessment for patients with chest pain: the relation of each to outcome. Med Care 1981;19:255-72.

57 Greenfield S, Lewis CE, Kaplan SH, Davidson MB. Peer review by criteria mapping: criteria for diabetes mellitus. The use of decision-making in chart audit. Ann Intern Med 1975;83:761-70.

58 Palmer RH, Strain R, Maurer JV, et al. A method for evaluating performance of ambulatory pediatric tasks. Pediatrics 1984;73:269-77.

59 Kemper KJ, Fink HD, McCarthy PL. The reliability and validity of the pediatric appropriateness evaluation protocol. Quality Review Bulletin 1989;March:77-80.

60 Kemeny ME, Hargreaves WA, Gerbert B, et al. Measuring adequacy of physician performance. A preliminary comparison of four methods in ambulatory care of chronic obstructive pulmonary disease. Med Care 1984;22:62031 .

61 Gerbert B, Hargreaves WA. Measuring physician behavior. Med Care 1986;24:838-47.

62 Hopkins A. Approaches to medical audit. 7 Epidemiol Community Health 1991;45:1-3.

63 Wilson A, McDonald P. Comparison of patient questionnaire, medical record, and audio tape in assessment of health promotion in general practice consultations. $B M \mathcal{F}$ 1994;309:1483-5.

64 Tugwell P, Dok C. Medical record review. In: Neufeld VR, Norman GR, eds. Assessing clinical competence. New York: Springer, 1985; 142-82.

65 Van der Weide WE, Verbeek JHAM, Van Dijk FJH, et al. An audit of occupational health care for employees with low-back pain. Occup Med 1997;47:294-300.

66 Koes BW, Van Tulder MW, Van der Windt WM, et al. The efficacy of back schools: a review of randomized clinical trials. $\mathcal{F}$ Clin Epidemiol 1994;47:851-62.

67 Van Tulder MW, Koes BW, Bouter LM. Conservative treatment of acute low back pain: a systematic mega-review of 81 randomized clinical trials of 11 interventions. In: Van 
Tulder MW, Koes BW, Bouter LM, eds. Low back pain in primary care. Effectiveness of diagnostic and therapeutic interventions. Amsterdam. EMGO-I Geneeskunde VU, 1996:205-43.

68 Van Amstel RJ, Buijs PC. Voor verbetering vatbaar. De samenwerking tussen huisarts en bedrijfsarts bij sociaal-medische begeleiding (Guidance of sickness absence: cooperation of occupational physician and general practitioner). Amsterdam: NIA-TNO, 1997.

69 Vlaeyen JW, Kole-Snijders AM, Boeren RG, et al. Fear of movement/(re)injury in chronic low back pain and its relation to behavioral performance. Pain 1995;62:363-72.

70 Bloemhoff A, van Putten DJ, van Duivenbooden JC Beoordelingsrichtlijnen voor arbeidsgeschiktheid. Deel 1. Han- dleiding met functie-eisen en belastbaarheidsbeperkingen voor 64 beroepen in de bouwnijverheid. (Part 1. Manual with work demands and functional disabilities for 64 occupations in the construction industry.) Amsterdam: Stichting Arbouw, 1994;

71 TNO Preventie en Gezondheid. Beoordelingsrichtlijnen voor arbeidsgeschiktheid. Deel 2. Achtergrond en onderbouwing van de functie-eisen en belastbaarheidsbeperkingen voor 64 beroepen in de bouwnijverheid. (Part 2. The base for work demands and functional disabilities for 64 occupations in the construction industry.) Amsterdam: Stichting Arbouw, 1994.

72 Nisbett RE, Caputo C, Legant P, et al. Behavior as seen by the actor and as seen by the observer. F Person Soc Psychol 1973;27:154-64.

\section{Vancouver style}

All manuscripts submitted to Occup Environ Med should conform to the uniform requirements for manuscripts submitted to biomedical journals (known as the Vancouver style.)

Occup Environ Med, together with many other international biomedical journals, has agreed to accept articles prepared in accordance with the Vancouver style. The style (described in full in the $\mathcal{F} A M A[1]$ ) is intended to standardise requirements for authors, and is the same as in this issue.

References should be numbered consecutively in the order in which they are first mentioned in the text by Arabic numerals on the line in square brackets on each occasion the reference is cited (Manson[1] confirmed other reports[2][3][4][5]). In future references to papers submitted to Occup Environ Med should include: the names of all authors if there are three or less or, if there are more, the first three followed by et al; the title of journal articles or book chapters; the titles of journals abbreviated according to the style of Index Medicus; and the first and final page numbers of the article or chapter. Titles not in Index Medicus should be given in full.

Examples of common forms of references are:

1 International Committee of Medical Journal Editors. Uniform requirements for manuscripts submitted to biomed journals. $\mathscr{F} A M A$ 1993;269:2282-6.

2 Soter NA, Wasserman SI, Austen KF. Cold urticaria: release into the circulation of histmaine and eosinophil chemotactic factor of anaphylaxis during cold challenge. chemotactic factor of anaphylax

3 Weinstein L, Swartz MN. Pathogenic properties of invading micro-organisms. In: Sodeman WA Jr, Sodeman WA, ing micro-organisms. In: Sodeman WA Jr, Sodeman WA, eds. Pathologic physiology, mechanism
phia: W B Saunders, 1974:457-72. 